\title{
PPPL-2381
}

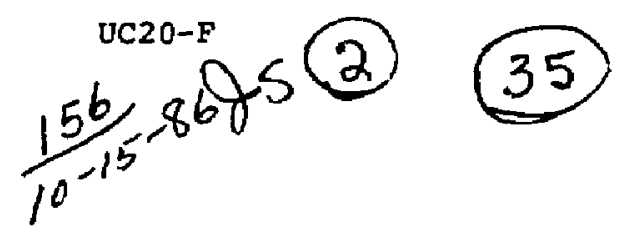

$$
\begin{aligned}
& \text { PPPL--2381 } \\
& \text { DE87 } 000665
\end{aligned}
$$

\section{A MULTIPLE TRACK DOPPLER-SHIFT SFECTROSCOPY SYSTEM FOR TFTR NEUTRAL BEAM INJECTORS}

J.H. Kamperschroer et al.

SEPTEMBER 1986

\section{PLASMA \\ PHYSICS \\ LABORATORY}

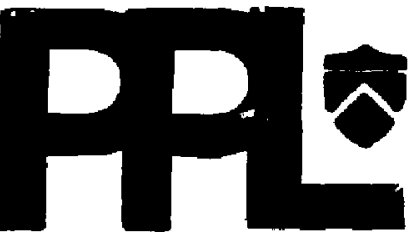

PRINCETON UNIVERSITY

PRINCETON, NEW JERSEY

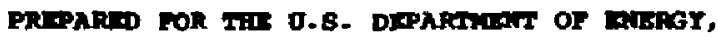
UWDER CONGACS DE-ACO2-76-CaO-3073. 


\section{DISCLAIMER}

This report was prepared as an account of work sponsored by an agency of the United States Government. Neither the United States Government nor any agency thereof, nor any of their employees, makes anj warranty, express or implied, of assumes any kgal liability or responsibility for the accuracy, completeness, or usefulness of any information, apparatus, product, or precess disclosed, or represents that its use would not infringe privately owned rights. Reference herein to any specific commercial product, process, or service by trade name, trademerk, manufacturer, or otherwise does not necessarily constitute or imply its endorsement, recommendation, or favoring by the United States Government or any agency thereof. The views and opinions of authors expressed herein do not necessarily state or reflect those of the United States Goverament or any agency thereof. 
A MULTIPLE TRACK DOPPLER-SHIFT SPECTROSCOPY SYSTEM EOR TETR

NEUTRAL BEAM INJECTORS

J.H. Kamperschroer, H.H. Kugel, M.A. Reale, S.L. Hayes, G.A. Johnson, a) J.L. Lowrance, P.A. Shah, b) P. Sichta, B.W. Sleaford, C) M.D. Williams, and P.M. Zucchinod)

Princeton Plasma Physics Laboratory, Princeton University, Princeton, New Jersey 08544

\section{ABSTRACT}

A Doppler-shift spectroscopy system has been installed on the TFTR neutral beam injection system to measure species composition during both conditioning and injection pulses. Two intensified vidicon detectors and two spectrometers are utilized in a system capable of resolving data from up to twelve ion sources simultaneously. By imaging the light from six ion sources onto one detector, a cost-effective system has been achieved. Fiber optics are used to locate the diagnostic in an area remote from the hazards of the tokamak test cell allowing continuous access, and eliminacing the need for radiation shielding of electronic components. Automatic hardware arming and interactive data analysis allow beam composition to be computed between tokamak shots for use in analyzing plasma heating experiments. Measurements have been made using lines of sight into both the neutralizer and the drift duct. Analysis of the data from the drift duct is both simpler and thore accurate since only neutral particles are present in the beam at this location. Comparison of the data taken at these two locations reveals the presence of partially accelerated particles possessing an estimated 1/e half-angle divergence of $15^{\circ}$ and accounting for up to $30 \%$ of the extracted power.

a) Permanent address: Applied Technology Associates, Mt. Laurel, New Jersey.

b) Present address: Dow Jones Company Inc., South Brunswick, New Jersey.

c) Permanent address: GA Technologies, Inc., San Diego, California.

d)Permanent address: Department of Astrophysical Sciences, Princeton University, Princeton, New Jersey. 


\section{INTRODUCTION}

To date, neutral bean injectors have successfully served as auxiilary heating systems on many different magnetic fusion devices, inciuding tokamaks, $^{1-5}$ mirror machines, ${ }^{6}$ and stellarators, 7 The present generation of large tokamaks, the Tokamak Eusion Test Reactor (TFTR), the Joint European Torus (JET), and JT-60, all employ neutral beam injectors as part of their auxiliary heating systems. In addition, the Mirror Fusion Test Facility (MFTE) is designed to employ neutral beams to both heat and fuel the mirror plasma. Design parameters from these impressive systems vary fron 10 to $20 \mathrm{MW}$ in power and 2 to 10 seconds in pulse length. $8-11$ at the power levels present within these systems, it is imperative to quantify accurately the properties of the beam within the injectors, both to preclude any damage to internal components and to optimize performance. In order to characterize the enerzy confinement of beam-heated tokamak plasmas, ${ }^{12}$ it is important to diagnose the injected neutral beams as well as possible. Those parameters considered most important for confinement studies are the total injected power and the beam composition. The latter quantity, beam composition, is important because hydrogen isotope neutral beam systems, based on extraction of positive ions, are not monoenergetic. Plasma sources in these systems produce three ionic components $\mathrm{D}^{+}, \mathrm{D}_{2}^{+}$, and $\mathrm{D}_{3}{ }^{+}$(or similar ions for hydrogen or tritium). During the neutralization process the molecular ins dissociate, and upon equipartition of energy among the constituents produce half-energy and thirdenergy atoms in addition to the full-energy atoms. The relative proportions of the beam in the three energy levels are important since they penetrate and heat the plasma differently. 
Optical diagnosis of neutral beams has become popular both because it is difficult to probe, high power beams, due to their high power density, and because many other techniques. such as calorimetry and momentum analysis, require stopping most or all of the beam and cannot be utilized on actual injection pulses. Nonperturbing optical techniques avoid both of these problems. Foremost among these is Doppler-shift spectroscopy. Developed at the Lawrence Berkeley Laboratory (LBC), 13 similar systems have been constructed and utilized at Eontenay-aux-Roses, 14 Cuinam Laboratory, 15 Lawrence Livermore National Laboratory, ${ }^{16}$ GA Technologies, ${ }^{17}$ and the Japan Atomic Energy Research Institute (JAERI). ${ }^{18}$ Measurements of the beam: composition, ${ }^{14-16,19-21}$ transverse velocity distribution, $13,14,16,20,21$ and spatial enissivity variation $14,22,23$ have been made using this technique. In the case of the former measurement, knowledge of excitation cross sections and the evolution of the many charged and neutral components of the beam is required. 20,24 Measurement of the velocity distribution requires quantitative information for all phenomena that can cause broadening of the Doppler-shifted lines. 25 The system described in this paper has been developed for, and employed on, the injectors for TFTR. Preliminary results of beam composition measured at different locations within the injeotors are presented. Use of this diagnostic to determine beam divergence from the transverse velocity distribution of our system is still under development.

Figure 1 is a schematic diagram of the TETR neutral beam Doppler-shift spectroscopy system. Long optical fibers are employed, allowing the spectrometer and detector to be placed in an area away from the electromagnetic and neutron radiation hazards of the tokamak. Decoupling from the environment of the tokamak eliminates the need for neutron shielding, thus providing access to the instrument, and reducing the magnetic shielding 
problem to manageable proportions. This decoupling is attained at the price of a tolerable loss of signal. A novel feature of the TFTR system is that one detector, a two-dimensional intensified vidicon, is used to gather simultaneous data from up to six different ion sources. As a result, two such systems cas monitor all eleven ion sources presentiy installed on TFTR and the one ion source on the neutral beam test stand.

The TFTR CICADA 26 computer system is employed to communicate with this instrument, to analyze the data, and to present the data to the operator.

\section{SYSTEM DESCRIPTION}

\section{A. FIBER OPTICS}

Figures 2 and 3 are schematic representations of elevation and plan views, respectively, of a TFTR neutral beam injector. There are four neutral beam injectors on TETR, each capable of accommodating up to inree $10 \mathrm{~cm} x$ $40 \mathrm{~cm}$ LBL ion sọrces. 27 Beamlines are numbered 2, 3, 4, and 5 proceeding counterclockwise around the tokamak, with beamline 2 being in a normally counter-injecting direction and beamlines 3,4 , and 5 being co-injectors. Ion scurces on a beamline are referred to as $A, B$, and $C$ from left to right viewed toward the tokamak from behind the ion sources. (Ion source $4 \mathrm{~A}$ is source $\mathrm{A}$ of beamline 4.) Source 5B has not been installed, in place of it, one beamline has been reserved for a test facility with its one ion source connected to the power system for $5 B$.

The arrangement of the $10 n$ sources is such that the $10 \mathrm{~cm}$ dimension is horizontal and the $40 \mathrm{~cm}$ dimension vertical. This results in the grid rails being oriented horizontally. Viewing ports are installed on the top of each optical dlagnostic box located between the ion source enclosure and the source isolation valve. A direct line of sight, shown in Fig. 2, allows the velocicy 
distribution perpendicular to the grid rails to be observed. Use of a mirror (not shown), internal to the box, accommodates a line of sight, shown in Fig. 3, parallel to the rails. The included angle between the beam and viewing lines of sight is $60^{\circ}$ with the beam coming toward the observation point, yielding blue-shifted $D_{\alpha}$ (or $H_{\alpha}$ ) light. Also shown in Fig. 2 is a $60^{\circ}$ line of sight into the drift duct at the end of the beam box. While this view exists on both the heating beams in the tokamak test cell and on the neutral beam test stand, it has been used so far only on the test stand.

A lens-coupled fiber optic system is used to deliver collimated light to the spectrometer. Accurate collimation is required if the transverse velocity distribution is to be determined from the line broadening. Light is coliected by a Cason Model FD, $135 \mathrm{~mm}, \mathrm{f} / 2$ photographic lens. By placing a $600 \mu$ fiber at the focus of the lens, light collimated to within a half-angle of $0.13^{\circ}$ is collected.

As part of the light collection system, it is important to determine that portion of phase space being sampled by this diagnostic since it differs from other diagnostics measuring the same parameters. In ganeral, many of the different diagnostics measuring the same parameters are complementary, rather than redundant, since they usually are sampling different portions of the beam's phase space. In this case, the line of sight encompasses the entire vertical extent of the ion source, hence all of the $y-, y^{\prime}$-phase space is sampled. ( $Y$ is defined to be the vertical coordinate, $x$ the horizontal coordinate, with $x^{\prime}$ and $y^{\prime}$ defined as the angles between the trajectory and the $x$ - or $y$-coordinate, respectively.) The same is not true in the horizontal plane. Here, the ion surce is $10 \mathrm{~cm}$ kide and the collimation cylinder is $6.4 \mathrm{~cm}$ in diameter, crossing the beam axis at a point $60 \mathrm{~cm}$ downstream from the Ion source. Eigure 4 shows that portion of $x$-pnase space, at the ion 
source, from which particles are emitted into the field of view. Those particles emitted from the source within the phase space enclosed by the two diagonal lines and $x= \pm 5 \mathrm{~cm}$ have trajectories that lie within the field of view. Assuming a divergence parallel to the grid rails of $0.4^{\circ}$, uniform extraction across the ion source, and Gaussian weighting of emission angles, 657 of the extracted beam passes through the field of view.

The fiber used is plastic clad silica with a numerical aperture of 0.22 , matching the $f / \#$ of the collection lens. A cuntinuous length of $f$ iber was pulled rrom the lens to the spectrometer and field-terminated at both ends, in a concerted effort to reduce connection loss. An SMA connector was used to position the siber at the focal point of the collection lens and a linear array of six fibers was constructed at the spectrometer end, Overall Iength of the fiber is $130 \mathrm{~m}$ yielding $a .1 \mathrm{db}$ attenuation of the red $D_{\alpha}$ light. Light Irom the linear array is coupled directly into the slit of a spectrometer.

\section{B. DISPERSION AND DETECTION}

The use of a spectrometer and Optical Multichannel Analyzer 28 provides a system which gives complete spectral resolution of the Doppler-shift spectrum is a single pulse. While other systems used in neutral beam optical analysis also provide spectral resolution, this is the first that combines spectral resolution with multiple spectra capability on one detector.

I'wo Czerny-Turner spectrometers are in use as the dispersing elements in the instrument. One spectrometer, manufactured by SPEX Industries, has a one meter focal length and $f / g$ optics, the other, manufactured by Instruments $S A$, has a $64 \mathrm{~cm}$ focal length and f/5.6 optios. Both are operated with dispersion on the order of $5 \AA / m x$, glving a spectral range of $60 \AA$ on the detector. This is enough to accommodate the $40 \AA$ Doppler-shift of full-energy 120 keV deuterons from the unshifted $D_{\alpha}$ line. 
An EG\&G Princeton Applied Research Corporation (PARC) model 1254E red enhanced SIT vidicon serves as the detector. It has the advantage of offering off-the-shelf two-dimensional resolving capability. The array of pixel elements is $512 \times 512$ over an active area of $12.5 \mathrm{~mm}$ wide by $12.2 \mathrm{~mm}$ high. Detector resolution of \pm 2 channels is the 1 imiting factor in the resolution of the dispersion/detection system. Each fiber is imaged snto a 50 to 70 pixel high horizontal track across the face of the detector. Each of these tracks represents the spectral data of an ion source; the horizontal direction being wavelength and the vertical being proportional to the spacing between fibers. A track-to-track separation of 50 to 70 pixels is obtained by stacking the fibers, with core, cladding, and buffer, in a linear array at the entrance siit with core-to-core spacing of $1.7 \mathrm{~mm}$.

The gain control of the detector controller was modified to decode the two-bit control logic into four independent high voltage settings. With intensifier voltage settings of $9 \mathrm{kV}, 6.8 \mathrm{kV}, 5.6 \mathrm{kV}$, and $4.5 \mathrm{kV}$, gains approximating full, half, fourth, and eighth are attained. Reduced gain settings are convenient as the number of tracks is increased. Scanning thore tracks causes any given pixel to be read less frequently, resulting in increased signal accumulation, and possible saturation or nonlinear behavior.

Even though located $40 \mathrm{~m}$ from the center of the tokamak, transient magnetic fields, on the order of I $G$, affected the detector causing variations in the output when the tokamak pulsed. Magnetic shielding consisting of several layers each of Netic ${ }^{29}$ and Co-netic ${ }^{29}$ materials reduced the transient field levels to less than $0.1 \mathrm{G}$ and nonvarying operation was achieved. 


\section{DETECTOR INTERFACE ELECTRONICS}

An electronics module, referred to as the data stream controller (DSC), was developed to perform interface functions between the PARC 1216 detector controller (hereafter referred to PARC 1216) and the TFTR CICADA computer systom. This module resides in a CAMA crate and obtains its power from the crate. It receives timing information from CíCADA through CAMAC digital timed gate modules, and control information from a standard CAMAC first in, first out module (FIFO).

The DSC performs two functions in its interface role. It handles handshake control when command data are passed from the EIFO to the PARC 1216. More importantly, it supports data acquisition from the PARC 1216, acting as a buffer to two 24-bit caMaC dual port merory modules.

Detector set-up parameters are passed from the FIFO to the PARC 1216 vidicori controller via the DSC. In this capacity, the DSC performs the necessary handșhake and monitors the word stream to filter out and insert command words. It holds the RUN command, sent by CICADA, until it receives an initializing timing pulse. When this command is issued, the PARC $12: 6$ commences sending data; after one minute, the DSC issues a STOP oommand causing data transmission to cease.

Data are acquired by the DSC in one of two modes: transparent node or integration mode. In the transparent mode it merely performs handshake buffering between the PARC 12.16 and the dual port memory. A frame (one scan of all tracks) worth of data is passed to the dual port memory after aach frame. In the integration mode, it performs a sum of the data for each channel on a frame-by-frame basis. In this mode, the data sent to the dual port memory are the time integral of the signal over the programmed acquigltion time. 
The 16-tit-wide data stream from the 1216 contains 14 bits of spectral channel intensity data and lwo bits of synchronization information. The last bit specifies the end of frame, and is used by the DSC in its data buffering. In the integration mode, the dynamic range of the system is increased to 23 bits tnrough the sumation technique.

The [SS has four lines for receiving timing pulse information, These are stan, foreground acquisition, stop foreground acquisition, start background acquisition, and stop background acquisition. Until receipt of a start pulse on one of tilese input lines, the DSC Ignores the data being sent by the PARC 1216. Upon receiving the start pulse, the DSC starts accumulating data after the next end-of frame synchronization bit it finds. Data are accumulated until the end of frarle following the receipt of the stop pulse. The data are then transferved to the backgrouns or foreground dual port memory (depending $o n$ which set of input lines the data stream controller received the timing information).

After transmitting the data to the dual port memory, the DSC enters a playback mode in which the data are replayed through a digital-to-analog converter. This signal is presented on a front panel BNC as an analog output.

\section{COMPUTER CONTROL}

Systen set up, arming, data acquisition, and data analysis are all accomplished via the TFTR CICADA real time computer systen. Four softivare tasks are utilized. An interactive task allows an operator to define the detector scanning configuration; an event-driven task initializes the hardware each shot: an event-driven archival task creates archived raw data files on the central computer facility; and an interactive data analysis and display task can be used to fit and display the data to an operator at a terminal operating station (TOS). 
The interactive set-up task functionally replaces the PARC 1215 console. Through this menu controlled task, the operator defines the $x-$ and $y$ locations of the tracks on the detector, the detector gain, and the scar rate. This information is processed into a command string that is sent to the FIFO. This program also allows the operator to select those ion sources for which data are to be acquired and/or fit.

An event-driven task is run every shot to initialize the hardware. It obtains power system timing and detector set-up parameters from the data. base. It computes a timing envelope to encompass all sources for which data are to be acquired. Background acquisition commen with the first filament power supply to turn on. Beam data acquisition commences one scan prior to the first beam extraction. After computing the timing envelopes, the task loads the timing modules'and initializes the other hardware components. Beam firing and software sequencing are initiated by a harowired clock and liming system.

An interactive analysis and display task can be executed from a ToS once raw data disc files have been created. This program is a modified version of a program developed at LBL. ${ }^{30}$ It executes a nonlinear multiple regression fit, to the data to determine the Doppler-shifted line positions, widths, and amplitudes, and hence the amount of light associated with each peak. When performing the measurement in the neutralizer, knowledge of the amount of gas through which the beam has passed is necessary since the beam is in a transitory state at the point of observation. With estimates of the lineintegrated gas density and measurements of the line shapes and magnitudes, it is possible to determine the beam composition at the point of extraction. An evert-driven task capable of automatically performing the same function each pulse is under development. Processed data from this latter analysis task will be stored in a processed data base on an off-line vax cluster. 
II. RESULTS

A. MULTITRACK DATA

of the two instruments, the ore based on the 64 cm spectrometer is operational on TFTR beamlines 4 and 5 , with the position of the central ion source on beamline 5 (source $5 B$ ) dedicated to the neutral beam test facililty. Simultaneous data have been collected on up to four ion sources as shown in Fig. 5. During this pulse the beams were injecting into a TFTR plasma. A Polaroid of an $x, y, z$ monitor of the real time output of the detector controller is shown for sources $4 \mathrm{~A}, 4 \mathrm{~B}, 4 \mathrm{C}$, and $5 \mathrm{~A}$, top to bottom. The $z$ output is a function of the signal intensity and wavelength increases left to right. Beam energies for this pulse were $85 \mathrm{kV}$ for all beamline 4 sources and $87 \mathrm{kV}$ for $5 \mathrm{~A}$. Tie tracks corresponding to the test facility and to ion source 5C lie below these four and were not activated during this particular pulse, since those sources were not operating.

Four spectrally resolved lines are evident for each track, the rightmost being the unshifted $D_{\alpha}$ line and the other three the Doppler-shifted beam component lines. Right to left the blue-shifted lines correspond to thirdenergy, half-energy, and full-energy atoms (arising from extracted $\mathrm{D}_{3}{ }^{+}, \mathrm{D}_{2}{ }^{+}$, and $\mathrm{D}^{+}$, respectively). The white band of 1 ight overlaying these lines on some of the tracks represents ions that are only partially accelerace. These ions charge exchange with gas in the grid structure and do not fall through the entire accelerating potential. As will be shown below, these atoms are highly divergent and can comprise a significant fraction of the extracted beam power.

The species corresponding to fractions of $\mathrm{D}^{+}, \mathrm{D}_{2}{ }^{+}$, and $\mathrm{D}_{3}{ }^{+}$at the extraction plane for this pulse are $0.56,0.32$, and 0.12 , respectively, with little variation from source to source. Assuming equilibrium neutral 
fractions (a good assumption for the TFTR beamlines), these fractions correspond to injected neutral particle fractions of $0.29,0.44$, and 0.27 . Error bars are approximately $\pm 5 \%$ for each species, and are dominated by uncertainties in the line density of gas between the extraction plane and field of view of the instrument. This uncertainty in the line density is due primarily to uncertainties in the temperature of the gas in the neutralizer. 31 Agreement with typlcal values attained on test stands at $\mathrm{LBL}^{32}$ is within the error bars for the full-energy fraction but shows somewhat more $\mathrm{D}_{2}{ }^{+}$and less $\mathrm{D}_{3}{ }^{+}$than LBL, indicating siightly different gas efficiency.

\section{B. COMPARTSON OF DRIFT DUCT AND NEUTRALIZER MEASUREMENTS}

Data were also acquired at the drift duct location indicated in Fig. 2. There are several significant advantages to using this location to measure the bearn species. First, ions have been magnetically removed by the time the beam reaches this location. A smal' fraction fon the order of one percent) of the neutral particles reionize in the drift duct, but are quickly removed by the magnetic fields of the tokamak and do not affect the measurement. Ions are therefore not present to capture electrons into excited states. The only particles present of any significance are atoms at full-, half-, and third-energy. Therefore, the only cross sections required are for the excitation of these atoms into $n=3$ states via collision with background Eas molecules

$$
\underline{D}^{\circ}+D_{2} \rightarrow \underline{D}^{\circ}(n=3)+\ldots \cdot
$$

(underlining implies a beam particle) and this cross section is well know. 33 Second, the measurement is independent of the line-integrated gas density 
through which the beam has passed, and hence independent of any gas temperature effects taking place in the ion source or neutralizer. This is much simpler than the neutralizer case where 14 different types of particles and their excited states must be fallowed as a function of line-integrated gas density because the beam composition evolves from 100\% charged particles toward equilibrium fractions of ions and neutrals. Any uncertainty due to errors in the estimation of the integrated line density are eliminated. Third, the charge exchange background has disappeared and any uncertainties in how to subtract it are gone. Last, the measurement is performed close to the point of injection where one would ideally like to measure it.

Figure 6 shows data taken at the drift duct location on the test facility. Concomitant with the significant advantages described above are several drawbacks. The gas pressure at this position is sevaral orders of magnitude smaller than that in the neutralizer, yielding a signal that is several crders of magnitude smaller. Part of the reduced signal magnitude was recovered by opening the slits on the spectrometer to $700 \mu$, from $25 \mu$ for the neutralizer measurement. The penalty for opening the slit is that instrument broadening swamps velocity distribution broadening and deconvolving the divergence becomes difficult. Another drawback of the drift duct location is that the fraction of the beam being observed decreases, but only slightly from the $65 \%$ mentioned earlier to approximately $50 \%$.

By comparison, Flg. 7 shows data collected at the neutralizer location. Here the signal-to-noise ratio is improved, due to reasons just mentioned. One also notices that the background under the Doppler-shifted peaks is reduced when the measurcment is carried out in the drift duct. The relative amount of background to Doppler-shifted peak is reduced by approximately a factor of three compared to the neutralizer measurement. 
Based on a threefold reduction in signal over a distance of $7 \mathrm{~m}$, assuming a beam divergence of $1.45^{\circ}$ (1/e half-angle) perpendicular to the grid rails, as measured via least squares fit to thermocouple data, and assuming that the divergence parallel to the grid rails of the partially ascelerated particles is the same as the beam, one deduces that ihe divergence of these background particles is on the order of $15^{\circ}$ (1/e half-angle). Most of these particles never reach the end of the neutralizer. These partially accelerated particles would give $r$ ise to the non-Guassian beam profiles seen by others. 34

\section{III, SUMMARY}

A Doppler-shift spectroscopy system installed on the TETR neutral beam injectors has shown that simultaneous collection of data from several ion sources can be $\varepsilon$-hieved. Large $(600 \mu)$ core fibers were used because of their large cross section and hence large collection area, and because they are, relatively speaking, easy to work with. Care was taken to design the system with no fiber-to-fiber couplings and their inherent loss of light. As a result, signal-to-noise ratios attained indicate that time resolution approaching the millisecond level may be possible for the beam composition measurement. An electronic shutter, controlled by CICADA, has been installed inside the SPEX spectrometer to perform this exper:ment. Spacing the fibers 1.7 mm center to center at the entrance slit yields excellent vertical separation of the tracks while allowing simultaneous viewing of data from six Ion sources.

Experience has shown that the ideal location to monitor the composition of the nel.ial beam is in the drift duct connecting the beamline to the tokamak, not in the neutralizer. Concern over the exact shape of the background due to the partially accelerated particles is ameliorated by 
monitoring the signal in the duct since the background level is reduced threefold. Measuring the beam after the neutralization is complete eliminates the need to know the line density of the neutralizer. Hence the measurement becomes independent of the gas temperature distribution in the neutralizer and of the gas throughput into the ion source. Knowledge of well-known cross sections is all that is necessary to make the measurement.

The background of partially accelerated particles is believed to comprise a significant fraction of power extracted from the ion source. Waterflow measurements produce results which show oniy $70 \%$ of the extracted power delivered to the calorimeter when the deflection magnet is off. We believe that most of this power is in the form of highly divergent, partially accelerated particles, and can be seen in the Doppler-shifted spectroscopic data. Estimates of the divergence of these particles is $15^{\circ}$, and only a small fraction of them actually reach the tokamak. In order to optimize injector performance every effort should be made to minimize this background level.

\section{ACKNOWLEDGMENTS}

We wish to acknowledge the assistance of the 1ate Dr. C. F. Burrell of LBL who computed the conductances of the TFTR neutralizer, supplied the data used to compute beam fractions at the location of our line of sight, and whe at one point proposed a multiple source system similar to what has been constructed at PPPL. Also, Dr. Edward Theil of LBL assisted in installing the analysis code on the PPPL CICADA system. Discussions with Steve Turner of SAI, who fabricated a prototype fiber optic syster, aided us in our final design. The magnetic stielding calculations of ken wright are gratefuliy acknowledged as is the assistance of Tor O'Connor, Brian McCormack, and Jack Bartow in orgaslzing the fiber optic cable pull. The technical support of 
Greg Lemunyan, Bob Hoch, Frank Polom, Vince Mastrocola, Jim Dovicsak, Erank Vanreymersdal, Richard Such, Tom Devine, Dan 2ydorski, and Bill Harter was invaluable.

This work was supported by U.S. Department of Energy under Contract No. DE-ACO2-76CHO3O73. 
REFERENCES

${ }^{1}$. Eubark et al., Phys. Rev. Let,t. 43, 270 (1979).

${ }^{2}$ S.M. Kaye et al., Nucl. Fusion 24, 1303 (1984).

3. Murakami et al., Fusion Technol. 8,657 (1985).

4 J.C. DeBoo et al., Fiz. Plazmy 11, 68 (1985) [Sov. J. Plasma Phys. 11, 40 $(1985)]$.

5H. Murakami et al., Proceedings of the Tenth International Conference on Plasma Physics and Controlled Nuclear Fusion Research, London, 1984 (IAEA, Vienna, 1985), Vol 1, p. 87.

${ }^{6}$ D.e. Grubb et al., Phys. Rev. Lett. $\underline{53}, 783$ (1984).

$7_{G}$. Cattanei et al., Proceedings of the Ninth International Conference on Plasma Physics and Controlled Nuclear Fusion Research, Baltimore, 1982 (IAEA, Vienna, 1983), Vol. 2, p. 241.

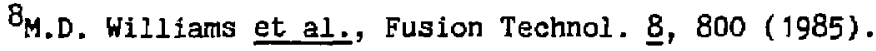

${ }^{9}$ C. Duesing, JET Joint Undertaking Report, JET-P(84) 07.

$10_{\mathrm{H}}$. Horiike et al., Rev. Sci. Instrum. $\underline{55}, 332$ (1984).

$11_{R}$. Stone, T. Duffy, and $J$. Vetrovec, Proceedings of the Tenth Symposium on Eusion Engineering, Philadelphiz, 1983 (IEE,, New York, 1983), Vol. 2, p. 1451 .

$1^{12}$ S.M. Kaye and R.J. Goldston, Nucl. Fusion 25, 65 (1985).

13C.F. Burrell, W.S. Cooper, W.F. Steele, and R.R. Smith, Proceedings of the Seventh Symposium on Engineering Problems of Fusion Research, Knoxville, 1977 (IEEE, New York, 1977), Vol. 1, p. 374.

14J.F. Bonnal, C. Braceo, C. Breton, C. de Michelis, J. Druaux, M. Mattioli, R. Oberson, and J. Ramette, J. Phys. D: Appl. Phys, 15, 805 (1982). 
15D. Stork and R.S. Hemsworth, Proceedings of the Eighth Symposium on Engineering Problems of Fusion Research, San Francisco, 1979 (IEEE, New York, 1979), Vol. 2, p. 1024.

${ }^{16}$ T.J. Orzechowski, M.R. Carter, and R.H. Munger, Rev. Sci. Instrum. 54,1615 (1983).

${ }^{17}$ T.R. McMahon and J.H. Kamperschroer, Bull, Am. Phys. Soc. 25, 973 '1980).

18. Okumura (private communication).

19.J. Bonnal, G. Bracco, C. Breton, C. de Michelis, J. Druaux, M. Mattioli, R. Oberson, and J. Ramette, Phys. Lett. 75A, 65 (1979).

${ }^{20}$ C.F. Burrell, W.S. Cooper, R.R. Smith, and W.F. Steele, Rev. Sci. Instrum. 51, $145 i(1980)$.

${ }^{21}$ G.A. Cattrell, A.R. Martin, and C. Padgett, Proceedings of the Second Joint Grenoble-Varenna International Symposium on Heating in Toroidal Plasmas, Como, Italy, 1980, Vol. 2, p. 945.

${ }^{22}$ G.A. Cottrell, J. Phys. E: Sci. Instrum. 15, 91 (1982).

${ }^{23}$ G.A. Cottre11, Rer. Sei. Instrum. 55, 1401 (1984).

${ }^{24} \mathrm{G}$. Bracco and J. Ramette, Euratom-C.E.A. Report No. EUR-CEA-FC-1061, 1980.

${ }^{25} \mathrm{G}$. Bracco, C. Breton, C. de Michelis, M. Mattioli, and J. Ramette, J. opt. Soc. Am. 71, 1318 (1981).

$26 \mathrm{~J}$. MeEnerney et al., Proceedings of the Eleventh Symposium on Fusion Engineering, Austin, 1985 (IEEE, New York, 1985) Vol. 1, p. 301.

27K.H. Berkner, C.F. Burrell, H.S. Cooper, K.W. Ehlers, A.E. Lietzke, H.M. Owren, J.A. Paterson, R.V. Pyle, and J.W. Stearns, Proceedings of the Eighth Symposium on Englneering Problems of Fusion Research, San Francisco, 1979 (IEEE, New York, 1979), Vol. 1, p. 214.

${ }^{28}$ Trademark of EG\&G Princeton Applied Research Corporation, Princeton, New Jersey. 
${ }^{29}$ Netic and Co-netic are traciemarks of the Magnetic Shield Division of Perfection Mica Company, Bensenville, Illinois.

30 The program is that utilized in reference 20 adapted to run on the LBL Neutral Beam System Test Facility computer system.

$31_{\mathrm{J}}$. Pamela, Rev. Sci. Instrum. 57, 1066 (1986).

${ }^{32}$. Pincosy (private communication).

33 I.D. Williams, J. Geddes, and H.B. Gilbody, J. Phys. B: At. Mol. Phys. 15, 1377 ( 1982$)$.

$34 \mathrm{~J}$. Kim and L. D. Stewart, Fusion Technol. 8, 1717 (1985) 
FIGURE CAPTIONS

Fig. i. Schematic of the TFTR neutral beam injector Doppler-shift spectroscopy system. Shown are the flow of beam, light, and data.

Fig. 2. Schematic elevation view of a TFTR neutral beam injector showing lines of sight, perpendicular to the ion source grid rails, in the neutralizer and drift duct.

Fig. 3. Schematic plan view of a TETR nelutral beam injector showing the neutralizer line of sight parallel to the grid rails.

Fig. 4. Phase space representation, at the ion source, of those particles emitted into the field of view of the collection optics. $X$ is the horizontal coordinate and $x^{\prime}$ is the angle a trajectory makes to the $x$ axis. Trajectories from the ion source emanating between the two diagonal lines are within the field of view.

Fig. 5. Polaroid showing the real time display of the image on the detector. The brightness of the trace is a function of the signal intensity falling on the detector. Top ion source is $4 \mathrm{~A}$, followed by $4 B, 4 C$, and $5 A$ on the bottom.

F1g. 6. Doppler-shifted spectrum obtained using the line of sight in the drift duct. Shown are the lines corresponding to the full-, half-, and third-energy atoms as well as ti: unshifted $D_{\alpha}$ line. 
Fig. 7. Doppler-shifted spectrum obtained using the line of sight in the neutralizer. Shown are the lines corresponding to the full-, half-, and third-esergy atoms as well as the unshifted $D_{\alpha}$ line. 


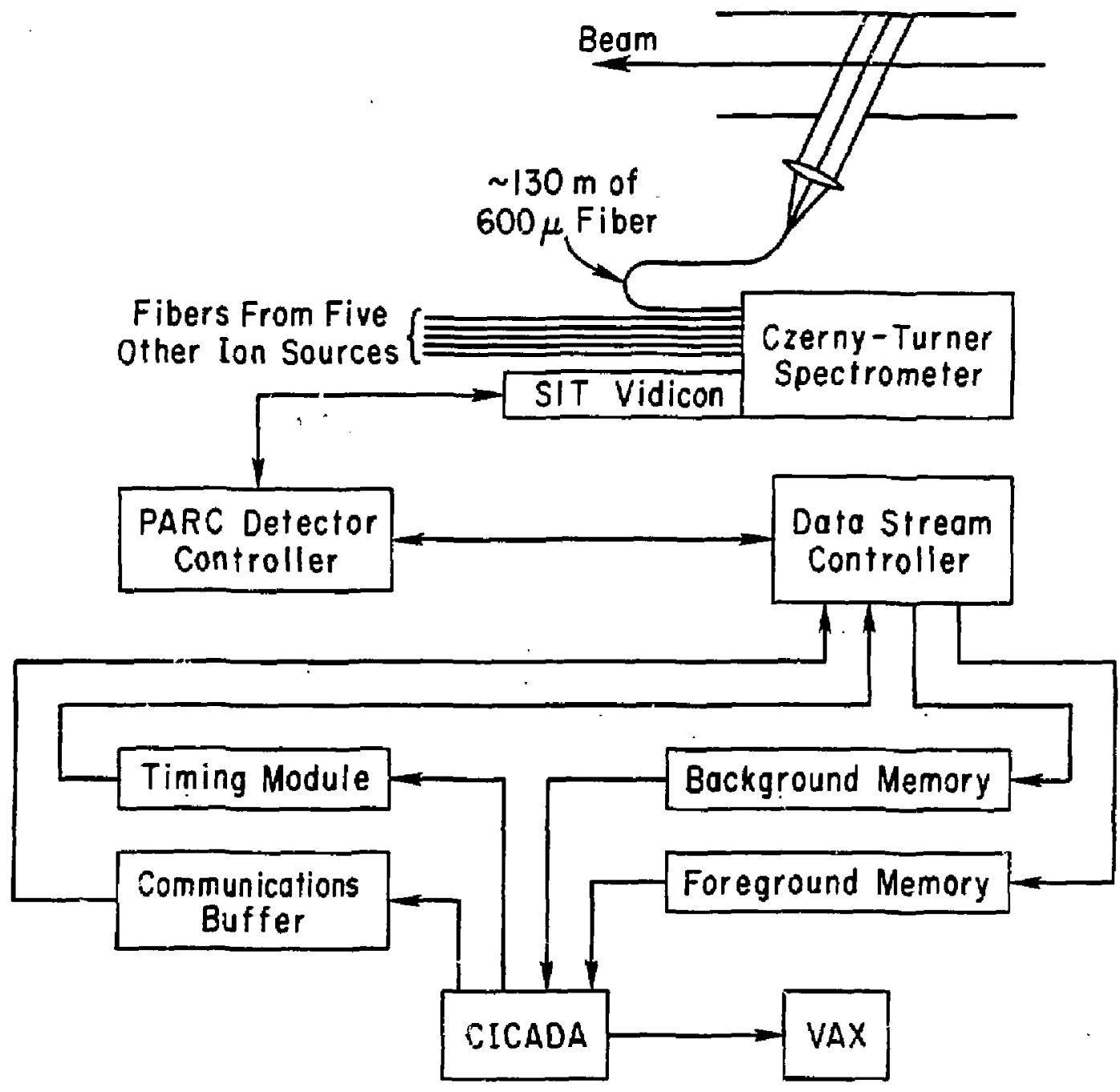




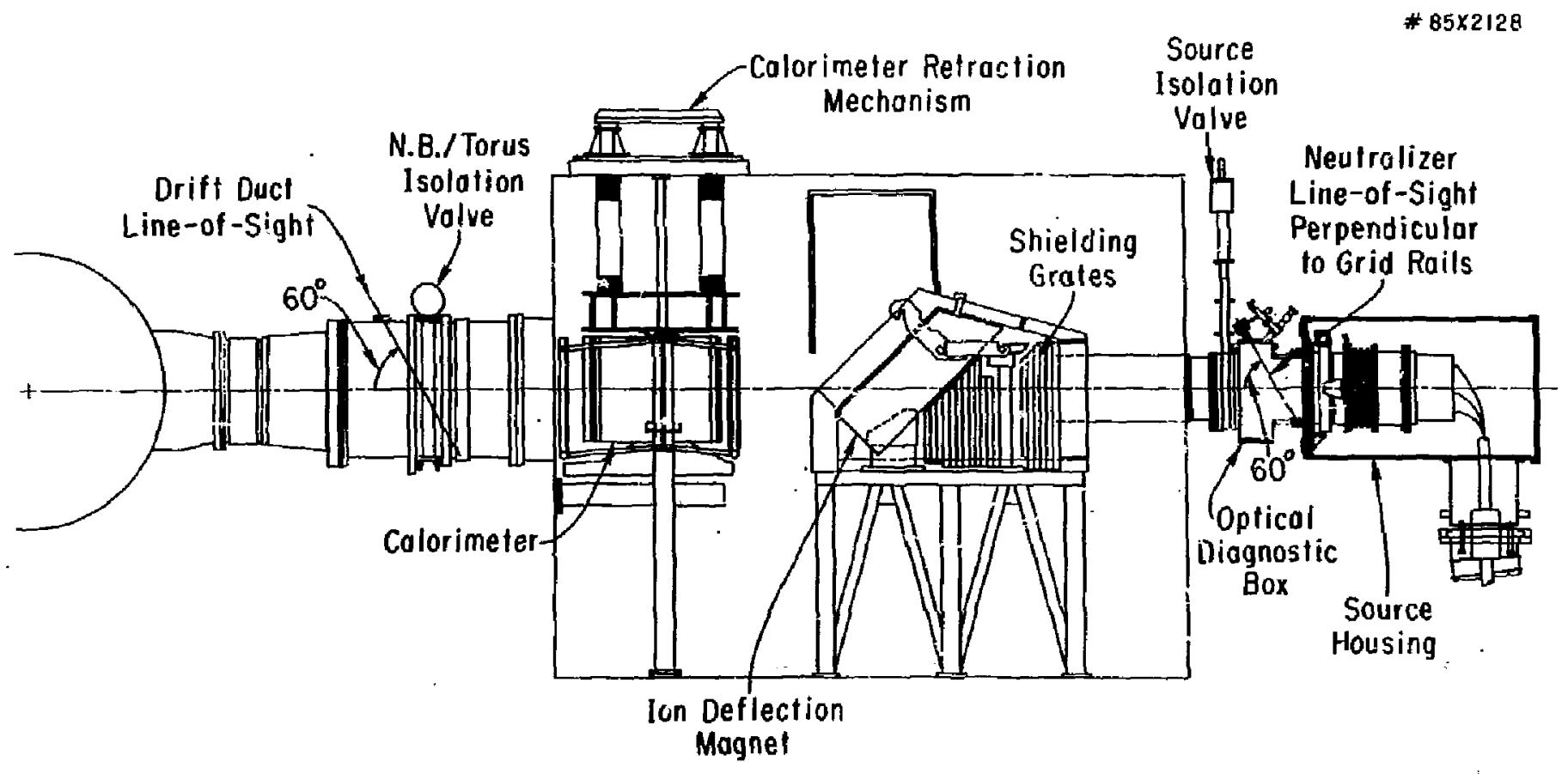




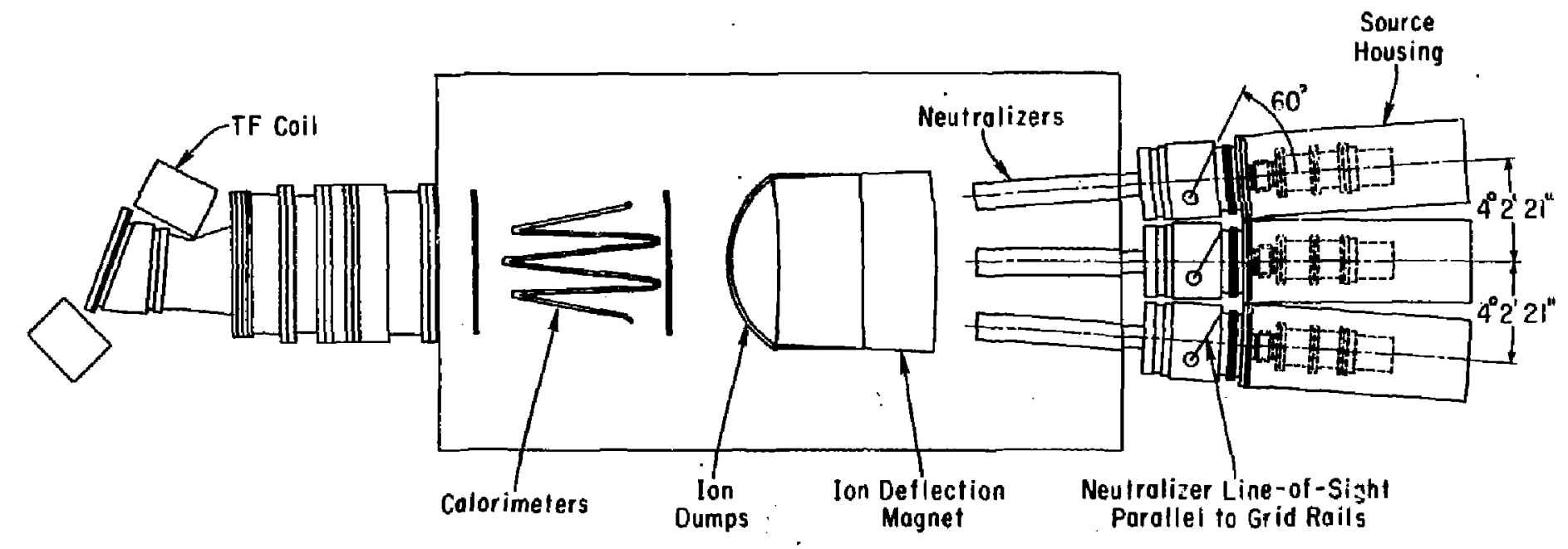

Fig. 3 


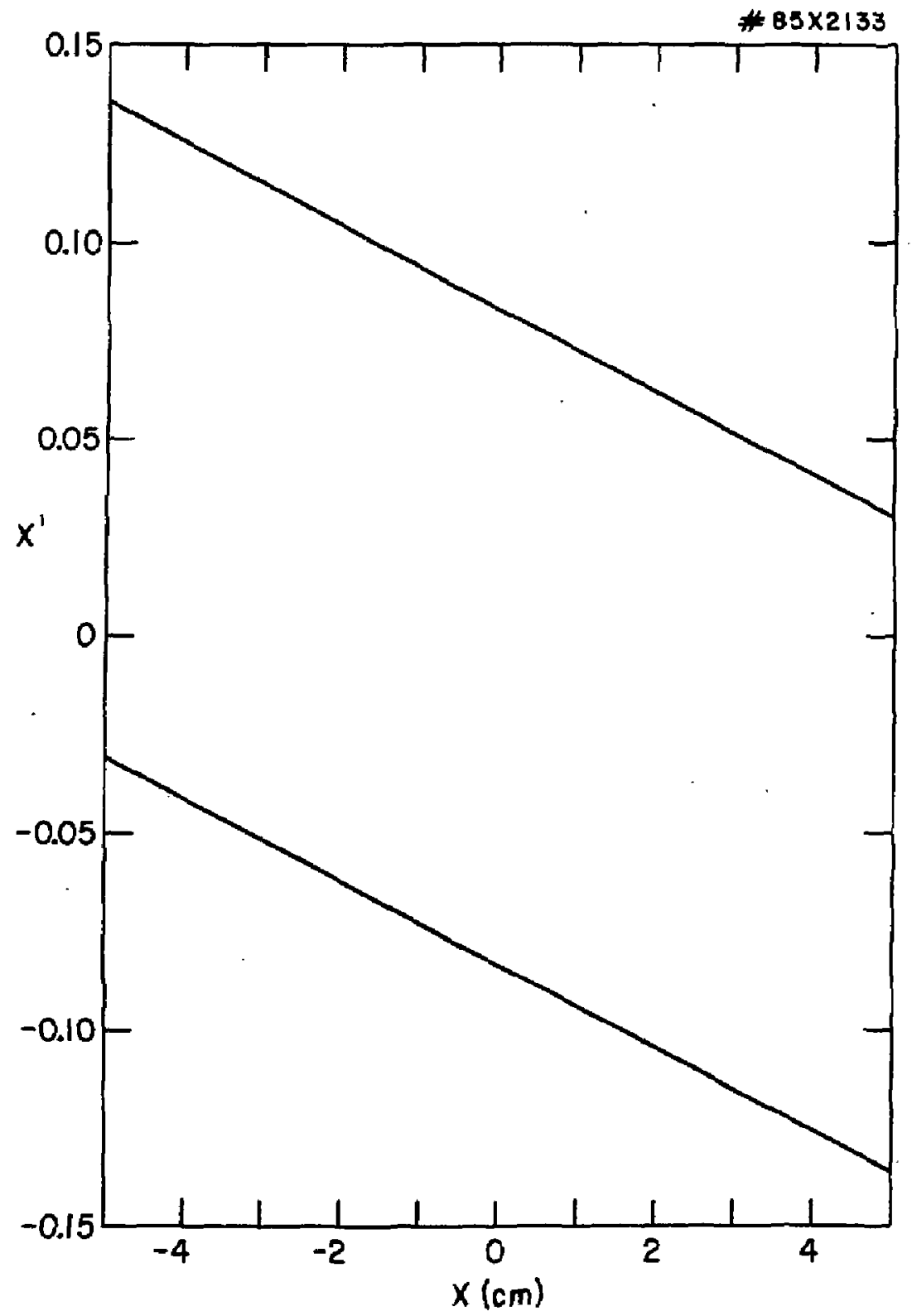

Fiqg. 4 


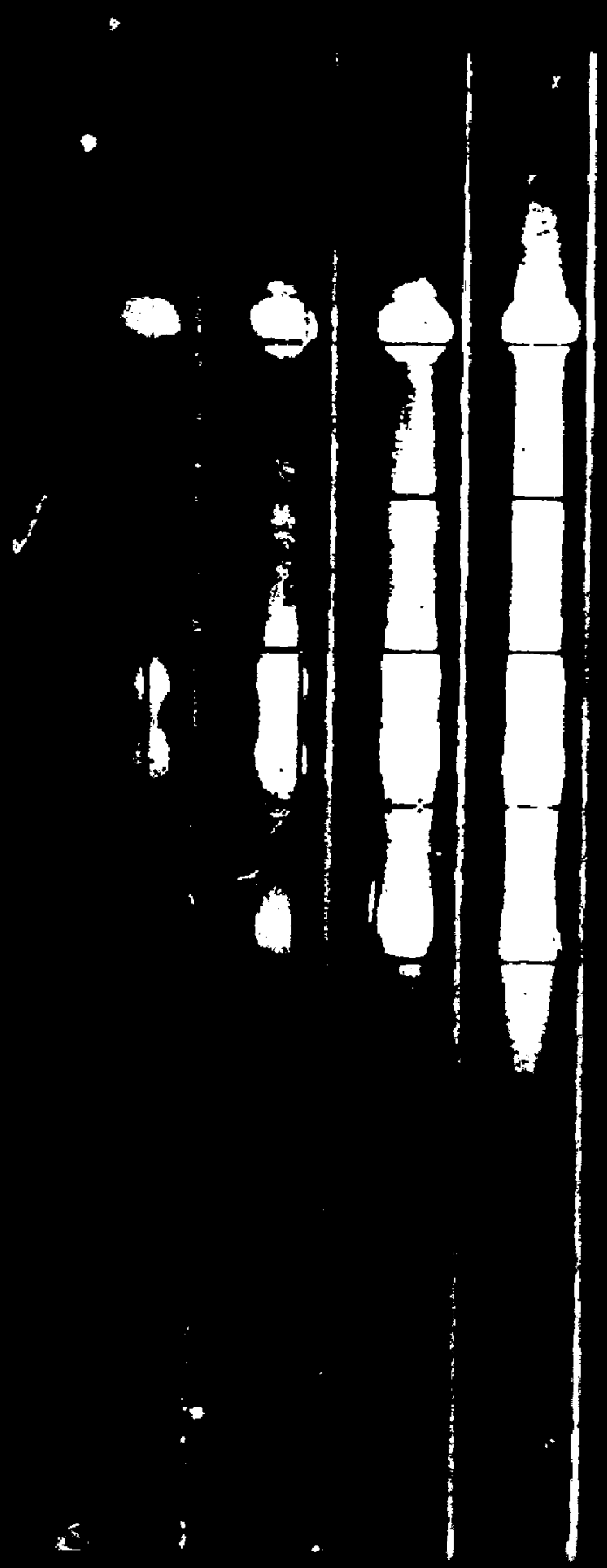

t.

3

in

羊

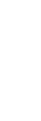




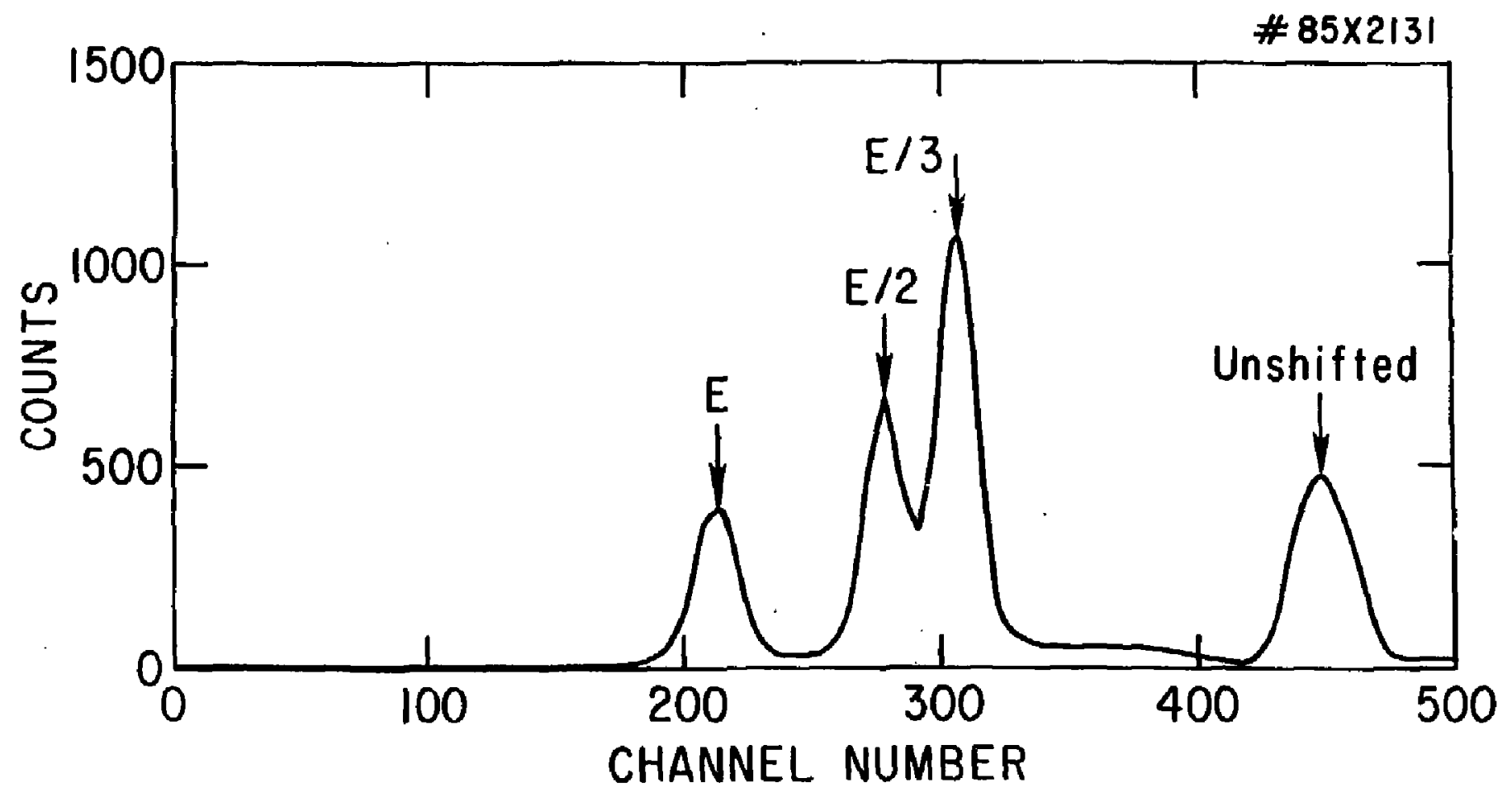

I

Fig. 6 
\# $85 \times 2132$

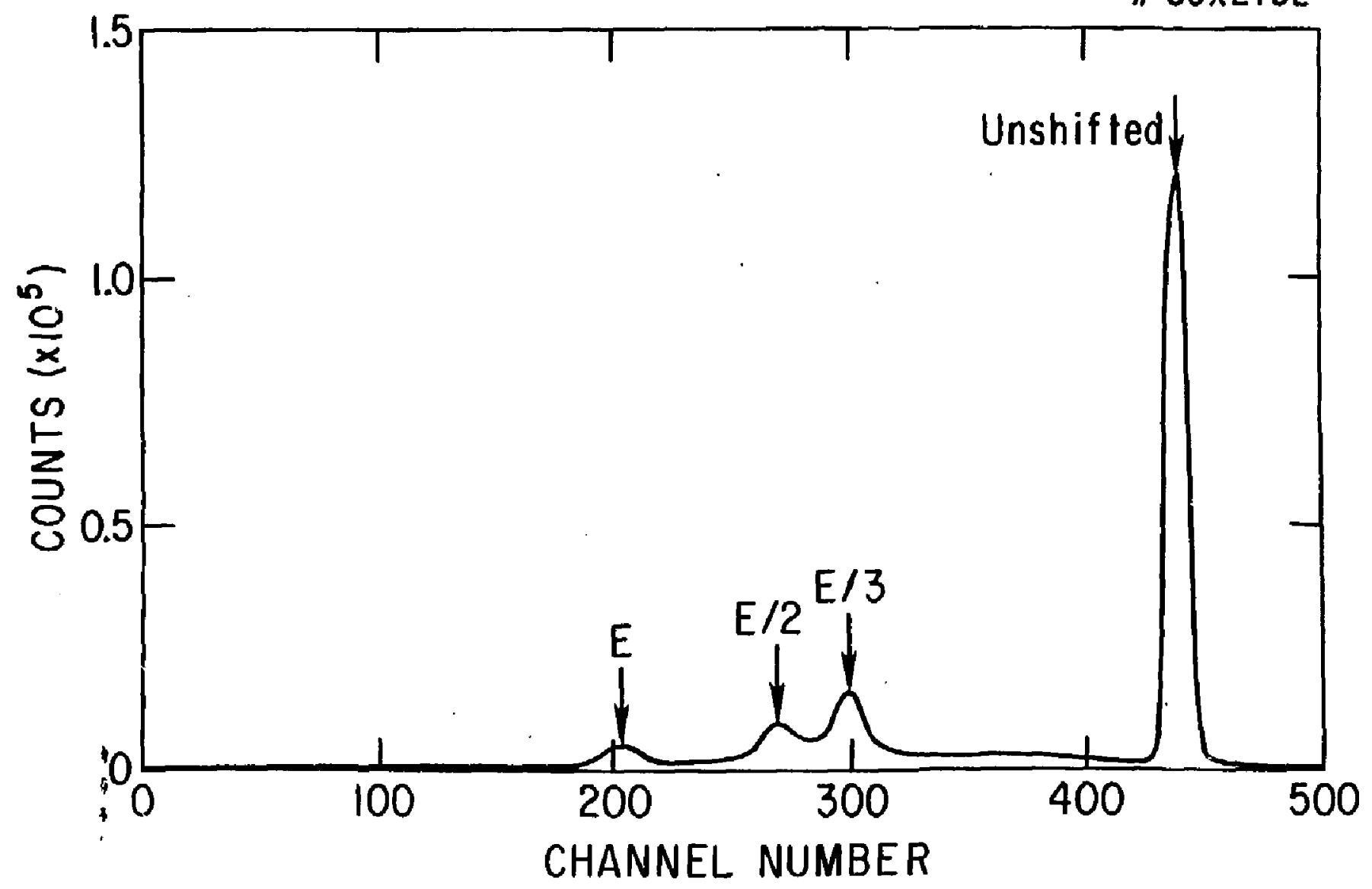

Fig. 7 
Plasme Res Lab, Austra Hat'l Unly, MUSTRALiA

Dr. Frank J. PaolonI, Unlv of Wollongong, AUSTRALIA

Prof, I,R. Imes, Filnders UntY., AUSTRALiA

Prof. M,H. Brennan, Unle Sydnoy, Australia

Prot, F, Cap, Inst Theo Phys, AuSTRIA

M. Goossens, Astronomlsch Instituut, BELGILA

Prof. R. Bouclque, Laborator liun voor Matuurkurtde, BELGILA

Dr. 0, Palumbo, Dg XI I fusion Prog. BELGILM

Ecole Royale Milltalre, Lob de Phys Plasmos, BELGIJM

Dr. P,H. 5akanake, Univ Estadual, BRRIL

LIb. \& Doc. Div.. Instttuto de Pusqulsas Espaciala, BReIL

Dr. C.R. Jemes, Unlv of Al berta, CANMA

Prof. J. Telehman, Unlv of Montreal, CAMADA

Or. H,M, Skarsgard, Unlv of Saskatcheman, CANNA

Prot. S.R. Sreanlvasan, UnIversity of Calgary, CANOA

Prof. Tudor H. Johnston, IMAS-Entrgl S, CANADA

Dr. Hannes Barnard. Unlv Brltish Columbla, CANADA

Dr. M.P. Bachynskt, MB Technologles, Inc., CAwnoA

Chalk RIver, Nuel Lab, CANAOA

Zhengus LI, SW Inst Physles, CHIMA

Librery, Tsing Hwe Unlversity. CHINA

Librarian, Institute of Phrsics, CHIMA

Inst Plasw Phys, Academla S1nica, CHIM

Dr. Pater Lukac, Komenskeho Univ, CECHOSLOVAKIA

The LIbrarlan, Cu!han Laboratory, ENGLANO

Prof. Schatzinan, Observatolre de N1Ce, FRANCE

J. Redet, CEN-GPG, FRance

JET Roeding Room, JET Joint Undertaking, ENGLAND

A Dupes Library, M Dupes LIbrary, FRANCE

Or. Tom Mul, Acodemy Blbllographle, hows kows

Preprlint LIbrary, Cent Res Inat Phys, HLwGNRY

Dr. R.K. Chhojlasl, Vlkran Unlv. ItDik

Dr. B. Dasgupte, Saha Inst, IRDIA

Dr. P. Kar, Physlcal Researeh Lab, INOIA

Dr. PhIIIIp Rosenau, Israel Inst Tech, ISRAEL

Prof. 5. Cupenmen, Tol Ayly Universelty, ISRAEL

Prot. G. RostegnI, Uniy DI Padova, ITAL:

Librerion, Int"I Crr Theo Phys, ITALy

MIss Clatio De Polo, Assoc ELRATOH-ENEA, ITALY

Bfblloteca, del GA ELRATOA, ITALY

Dr.'H, Yamto, Toshl bu Res L Dov, JAPAM

Direc. Dept. Lg. Tokenak Dev. HAERI, JAPAN

Prot. Nobuyukl Inoue, Unlversity of Tokyo, JAPAN

Rosearch Info Center, Nagora University, SAPAN

Prof. KyojI NIshIkowh, UnIY of HIroshinu, JAPAN

Prot. SIgeru MarI, MERI, JAPAN

Prot. 5. Tenake, Kyote UnIversity, JAPAN

Llorary, Kyoto Unlversity, JAPAN

Prof. Ichito Kawakeml, Nihon UnIY, JAPAN

Prof. Sotoshl IToh, Kyushu UnIversity, JAPAN

Dr. D.1. Chol, Adv, Inst Sel I Tech, KOREA

Tech Info DIvIsion, KAERI, KOREA gibllotheik, Fom-Inst Voor Plasma, NETHERLANDS

Prof. B.5. Lilley, Universlty of Walkato, NEw ZEALAND

Prof. J.A.C. Cabrel, Inst Superlor Taen, PORTUGAL

Dr, Octavien Potrus, ALI SLEA UnIversity, ROMANIA

Prot. M,A. Helloerg, University of Natal, SO AFRICA

Or. Johan de VIIIIers, Flasme Phystes, Nucor, SO AFRICA

Fusion Eiv, LIbrary, JEN, SPAIN

Prof. Hans Wlithelmson, Chalmers Univ Tach, SWEDEN

Dr. Lennort Stanfio, Univarsity of UMEA, SMEDEN

LIbrary, Royal Inst Tach, SWEDEN

Contre de Ruchercheson, Ecole Polytech Fod, SWITERLAND

Dr. Y.T. Toloi, Kharkov Phys Tech ins, USSR

Dr. 0,D. Ryutow, SIberian Acad 5ci, USSR

Dr. G, A, Ellsoev, Kurchatov Instlture, USSR

Dr. V.A. Glukhlkh, Inst Eloctro-Physlcal, USSR

Institute Gon. Physjas, USSR

Prof. T.J.M. Boyd, Univ Colloge $N$ Wales, WALES

Dr. K, SchIndler, Ruhr UnIversltat, W, GEAMANY

ASOEX Reading Rm, IPP/Maxt lanck-Insti tut fur

Plesmaphyslk, F,R.G.

Nuclear Res Estab, dulfci, Ltd, W. GERWANY

Librarlan, Max-Planek Instlitut, H. GERMAY

Bibllothek, Inst Piaseforsehung, W. GERMur

Prof. R.K. Janev, Inst Phys, YugosLavia 